\title{
periferio
}

\section{POLÍTICAS CURRICULARES NO ÂMBITO ESCOLAR: QUE SIGNIFICADOS EMERGEM DA LEITURA QUE OS PROFESSORES FAZEM DO DOCUMENTO CURRICULAR}

\author{
Vera Regina Souza dos Santos ${ }^{1}$ \\ Universidade Federal do Estado do Rio de Janeiro -UNIRIO
}

\section{Resumo}

Este artigo apresenta resultados de uma pesquisa de cunho qualitativo que buscou identificar os significados que emergem da relação entre os documentos curriculares gestados em nível governamental e as concepções e práticas pedagógicas dos professores e professoras no âmbito da escola. Partiu do pressuposto de que os sujeitos estão ativos nos processos sociais (CHIZZOTTI, 2006) e de que o documento curricular estruturado em instâncias governamentais, embora pretenda constituir-se no documento de currículo a orientar toda uma rede de ensino, não tem como prever situações e questões que surgirão no desenrolar do trabalho (BALL, 1997). Focalizou o ciclo de alfabetização da rede pública de ensino do município do Rio de Janeiro, que instituiu, no ano de 2012, a Casa de Alfabetização, agrupando os três primeiros anos do Ensino Fundamental. Teve como objetivos analisar a concepção pedagógica que orientou tal estruturação curricular e identificar a relação que com a proposta curricular estabeleceram professores e professoras que atuavam nos anos iniciais do Ensino Fundamental de uma escola dessa rede de ensino. Para a coleta de dados, o trabalho valeu-se da análise de documentos, de entrevistas e da observação participante.

Palavras-chave: política curricular; ciclo de alfabetização; currículo; prática pedagógica

\footnotetext{
1 Doutoranda em Educação - Universidade Federal do Estado do Rio de Janeiro (UNIRIO). Pesquisadora do Grupo de Estudos e Pesquisas em Avaliação e Currículo (GEPAC) da UNIRIO. verarssantos@yahoo.com.br
} 


\title{
periferio
}

\section{CURRICULUM POLICIES AT THE SCHOOL: WHAT THE MEANING THAT EMERGE THE READING TEACHERS THE CURRICULUM DOCUMENT}

\begin{abstract}
This article presents results of a qualitative research that sought to identify the meanings that emerge from the relationship between the curricular documents generated at the governmental level and the conceptions and pedagogical practices of the teachers in the scope of the school. It assumed that subjects are active in social processes (CHIZZOTTI, 2006) and that the curricular document structured in governmental instances, although it intends to be the curriculum document guiding an entire teaching network, can not predict situations and issues that will arise in the course of work (BALL, 1997). It focused on the literacy cycle of the public school system of the municipality of Rio de Janeiro, which established, in 2012, the House of Literacy, grouping the first three years of Elementary School. It aimed to analyze the pedagogical conception that guided such curricular structuring and to identify the relationship that with the curricular proposal established teachers and teachers who acted in the initial years of the Elementary School of a school of this network of education. For the data collection, the work was based on the analysis of documents, interviews and participant observation.
\end{abstract}

Keywords: curriculum policy; early years; curriculum; teaching practice 


\section{periferio}

Este trabalho apresenta resultados de uma pesquisa de cunho qualitativo que buscou identificar os significados que emergem da relação estabelecida entre os documentos curriculares gestados em nível governamental e as concepções e práticas pedagógicas dos professores e professoras no âmbito da escola. Focalizou o ciclo de alfabetização da rede pública de ensino do município do Rio de Janeiro, que instituiu, no ano de 2012, a Casa de Alfabetização, agrupando os três primeiros anos do Ensino Fundamental. Partiu do pressuposto que os indivíduos estão ativos nos processos sociais (CHIZZOTTI, 2006) e também que o currículo prescrito na instância governamental - embora pretenda constituir-se em o documento de currículo - nem sempre consegue prever situações que surgirão no dia-a-dia da escola (BALL, 1997). A investigação teve como objetivos analisar a concepção pedagógica que orientou tal estruturação curricular e identificar a relação que com ela estabeleciam os/as professores/ professoras que atuavam nos anos iniciais do Ensino Fundamental de uma escola dessa rede de ensino. Para a coleta de dados, o trabalho valeu-se da análise de documentos, entrevistas e observação participante. A partir da análise do documento Orientações Curriculares - elaborado pela Secretaria Municipal de Educação do Rio de Janeiro - buscou-se apreender o sentido da proposta prescrita no âmbito governamental para a Casa de Alfabetização. E, para a apreensão da relação estabelecida com este documento, assim como dos significados que emergiram da leitura que dele fizeram os profissionais do magistério que estão no cotidiano da escola, atuando em turmas dos três primeiros anos, foram analisados documentos que registravam propostas curriculares dos profissionais de uma escola que conta com turmas dos anos iniciais do Ensino Fundamental $\left(1^{\circ}\right.$ ao $5^{\circ}$ anos, incluindo o agrupamento designado como Casa de Alfabetização): PPP (Projeto Político Pedagógico) e planejamentos do trabalho em sala de aula. Também foram realizadas entrevistas com esses profissionais. 


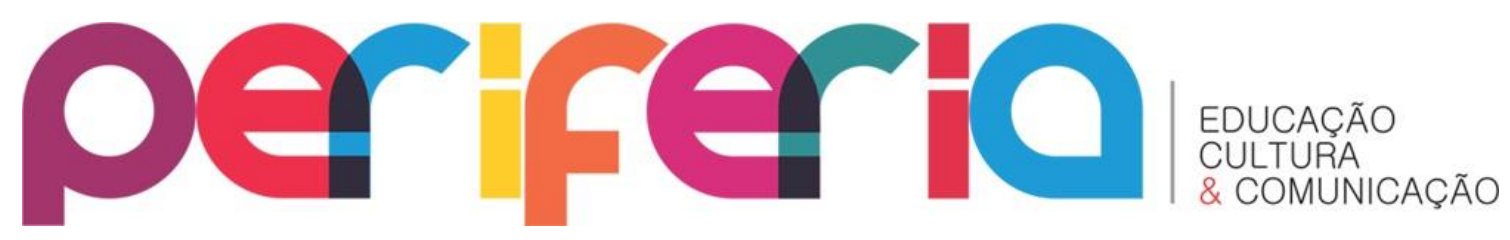

Num primeiro momento, houve a preocupação em situar o trabalho em relação ao debate acerca das políticas educacionais contemporâneas, identificando as principais orientações que têm caracterizado essas políticas e as implicações dessas orientações no cotidiano das escolas. Assim, de início, o estudo verifica como a relação entre os contextos macro e microestruturais das políticas públicas educacionais foi analisada por diferentes pesquisadores. Em seguida, analisa os significados que emergiram da relação estabelecida entre os documentos curriculares da política pública e as concepções e práticas dos/das professores/as.

\section{NEOLIBERALISMO E POLÍTICAS EDUCACIONAIS}

A análise do contexto macroestrutural, empreendida por Garcia (2010), Paro (2011) e Freitas (2012), sinalizou a existência de orientações neoliberais no campo da educação brasileira. Os estudos sinalizaram que vimos assistindo, há mais de duas décadas, no Brasil e no mundo, a transformações significativas no campo da educação. Tais transformações vêm se cristalizando, ao longo dos anos, num controle excessivo do Estado sobre os processos educativos, sem diálogo com aqueles que são os responsáveis pela condução do processo em nível micro - na escola, na sala de aula. Além disto, as pesquisas sinalizaram que, na última década, houve um recrudescimento das diretrizes neoliberais, com grande destaque para toda uma cultura da performatividade $^{2}$ que envolve os sujeitos e instituições, com a responsabilização destes pelo êxito ou o fracasso nos resultados do trabalho pedagógico, levando-se em consideração os índices medidos em testes de larga escala que vem se tornando cada vez mais comuns no país. Não obstante, o Estado pareceu desresponsabilizar-se pela condução do processo, desviando recursos públicos para instituições privadas e/ou fundações. Tal contexto vem produzindo competitividade entre indivíduos e instituições e,

\footnotetext{
${ }^{2}$ Cf Stephen Ball (2004).
} 


\section{periferio}

sobretudo, destruindo a dimensão ética da vida social, como apontado por diversos pesquisadores.

Garcia (2010), detendo-se sobre o discurso das reformas, que está presente em documentos elaborados por organismos internacionais $\mathrm{e}$ nacionais, afirmou que "as reformas atuais são práticas globais que visam a mudanças nos padrões de regulação social e nos regimes éticos que capacitam os sujeitos para as relações sociais" determinando qual lugar cabe a cada um. Segundo ela, são, "além de um conjunto de direções e princípios, esforços calculados para inscrever certas racionalidades políticas nas sensibilidades, nas disposições e na consciência dos indivíduos (...)" (GARCIA, 2010, p.446). Embora a autora afirme não ser possível dizer que a política educacional brasileira seja uma cópia das propostas internacionais que vem avançando ao longo dos anos, é possível, segundo ela, concordar que muitos elementos presentes no documento que orienta tal política estão em consonância com diretrizes internacionais para o campo da educação, ou seja, a presença de imperativos das políticas econômicas nas políticas educacionais. Nesta perspectiva, os documentos educacionais recentes ignoram o bem comum, a construção da identidade nacional, o compromisso com projetos sociais coletivos, a preocupação com a ordem e a segurança territorial e ideológica.

Paro (2011), em pesquisa sobre a estrutura da escola de Ensino Fundamental, analisando-a à luz do conceito de educação como prática democrática, sinalizou que a concepção de educação que se tem atualmente enfatiza o seu entendimento como apropriação de saberes mínimos, que serão úteis para o indivíduo prosseguir seus estudos, para situar-se na sociedade, para empregar-se ou para contribuir "com o desenvolvimento econômico e social do país" (PARO, 2011, p. 496). O autor questiona o trabalho centrado em conteúdos e informações, que se afastam muito daquelas que são qualidades que somente uma educação como apropriação da cultura proporcionaria. Segundo o autor, o currículo centrado e restrito a uma lista de conteúdos e informações "sonega ao indivíduo" o acesso a "outros elementos culturais igualmente valiosos" (PARO, 2011, p. 498). 


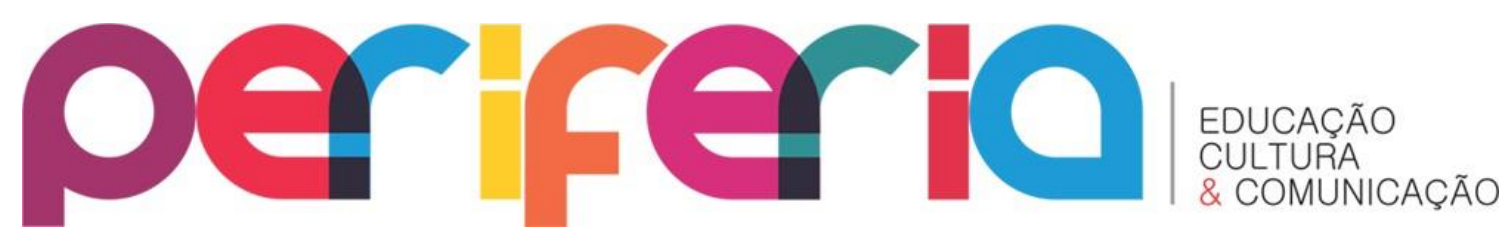

A cultura da performatividade, conforme sinalizada por Ball (2004), é hoje uma realidade presente nas políticas educacionais. Orientados por diretrizes da UNESCO e do Banco Mundial, diversos governos latino-americanos implantaram a cultura do controle de qualidade da educação, baseada em exames nacionais para medição do nível de aprendizagem dos estudantes. Tal política de controle da qualidade - centrada na perspectiva da performatividade - tem suscitado certos expedientes para que se alcance 0 desempenho desejado: o treinamento de estudantes para as provas, a exclusão de estudantes (em especial das classes populares) das escolas e dos sistemas. Além disto, os exames nacionais acabam gerando uma competição entre os indivíduos e as instituições - através do estabelecimento de rankings das instituições - e retirando do currículo conteúdos e conhecimentos mais locais, relacionados às singularidades de contextos socioculturais específicos; valorizando, ao contrário, conhecimentos supostamente tidos como universais. O resultado é o estabelecimento de uma lógica empresarial no meio educacional, baseada no individualismo, na competição, na negação das particularidades e na responsabilização dos sujeitos pelos fracassos ou sucessos, conforme nos sinaliza Freitas (2012).

Objetivando alertar para os riscos destas políticas no Brasil, o autor supracitado, a partir de evidências empíricas, analisa algumas características que marcam o discurso dos reformadores empresariais da educação expressão usada para denominar o grupo que se reuniu em torno do movimento Todos pela Educação ${ }^{3}$. Segundo ele, uma rede de institutos e fundações se desenvolve no país para apoiar tal discurso. Ele denomina de neotecnicismo o conjunto de ideias e ações que vem dando sustentação a este movimento:

30 movimento Todos pela Educação foi criado em 2006, resultado de uma série de movimentos que já vinham ocorrendo desde o governo de Fernando Henrique Cardoso. Constitui-se, desde o ano de 2014, em uma Organização da Sociedade Civil de Interesse Público (OSCIP) e congrega representantes de diferentes setores da sociedade. Atua basicamente em três eixos: geração de conhecimento técnico, mobilização e comunicação e articulação política e institucional. 


\section{periferio}

O tecnicismo se apresenta, hoje, sob a forma de uma "teoria da responsabilização", meritocrática e gerencialista, onde se propõe a mesma racionalidade técnica de antes na forma de "Standards", ou expectativas de aprendizagens medidas em testes padronizados, com ênfase nos processos de gerenciamento da força de trabalho da escola (controle pelo processo, bônus e punições), ancoradas nas mesmas concepções oriundas da psicologia behaviorista, fortalecida pela econometria, ciências da informação e de sistemas, elevadas à condição de pilares da educação contemporânea. Denominamos esta formulação "neotecnicismo" (FREITAS, 2012, p.383).

Segundo ele, esse neotecnicismo se estrutura em torno de três categorias: responsabilização, meritocracia e privatização. E a meritocracia está na base da proposta política neoliberal, atribuindo ao indivíduo, exclusivamente, a responsabilidade pelo êxito ou pelo fracasso nos resultados. Tal política negligencia as desigualdades de condições no ponto de partida entre os indivíduos e as instituições. Para a política neoliberal o que define os resultados é o "mérito" ou "esforço pessoal" de cada um. Freitas (2012) cita algumas consequências para o campo educacional: estreitamento curricular, com a valorização das disciplinas que serão alvo da avaliação padronizada; competição entre profissionais e escolas; pressão sobre o desempenho dos estudantes e preparação para os testes; fraudes nas avaliações; aumento da segregação socioeconômica dentro do território; aumento da segregação socioeconômica dentro da escola; precarização da formação do professor, através da dependência que este fica do apostilamento e de materiais estruturados; destruição moral do professor; destruição do sistema público de ensino e ameaça à própria noção liberal de democracia.

\section{A ANÁLISE DO CAMPO E SUA RELAÇÃO COM OS DOCUMENTOS}

Foi neste contexto educacional que se estruturou, no ano de 2012, no município do Rio de Janeiro, a Casa de Alfabetização, agrupamento dos três primeiros anos escolares, reunindo estudantes de seis a oito anos. A 


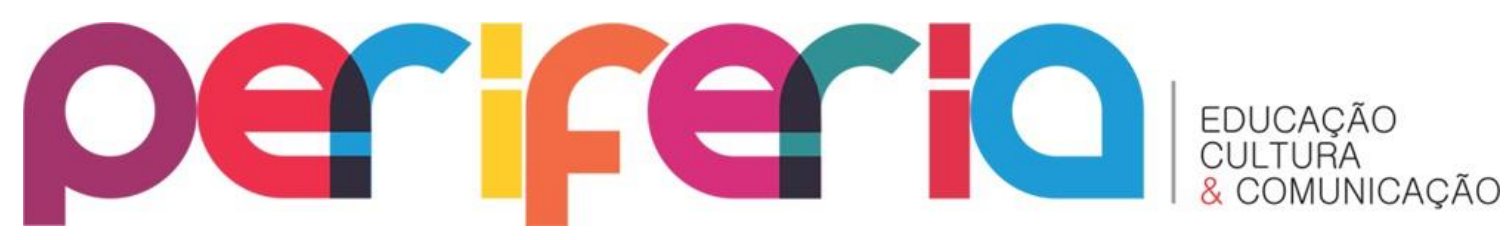

estruturação do tempo escolar, nessa rede, previa, até o ano de 2009, a organização por Ciclos de Formação, e todo o Ensino Fundamental estava organizado respeitando-se essa estrutura. A partir desse ano, sob uma nova administração municipal, foi decretada, pelo chefe do Poder Executivo, a extinção dessa estruturação, mantendo-se, entretanto, o agrupamento nos três primeiros anos de escolaridade. Nesse mesmo ano, a Secretaria Municipal de Educação encaminhou às escolas o documento Orientações Curriculares cadernos organizados por disciplinas, com orientações de objetivos, habilidades, conteúdos e sugestões de atividades a serem realizadas pelos/as professores/as nos diferentes anos escolares.

A análise do documento ${ }^{4}$ permitiu constatar que o que está proposto para os três primeiros anos do Ensino Fundamental, chamado, a partir de 2012 - como já informado - de Casa de Alfabetização, insere-se no que se convencionou chamar de ciclo de alfabetização. Embora não haja retenção do estudante do primeiro para o segundo ano e do segundo para o terceiro ano, não há uma proposição curricular que possa configurar o que é proposto em um Ciclo de Formação ${ }^{5}$. Assim, houve uma mudança na concepção desse agrupamento. O documento curricular proposto está estruturado por anos de escolaridade, dentro daquele agrupamento do tempo escolar. Muitos itens relacionados repetem-se em diferentes anos escolares, o que chamou a atenção de algumas professoras que atuavam com os grupos de estudantes daqueles anos escolares na escola pesquisada. A reflexão coletiva realizada na escola, favorecida pela institucionalização dos Centros de Estudos ${ }^{6}$,

\footnotetext{
${ }^{4}$ Cf. www.rio.rj.gov.br/web/sme/exibeconteudo?id=798880

${ }^{5}$ Conforme Fetzner (2009), o Ciclo de Formação caracteriza-se por uma estruturação que respeita o critério da aproximação da idade dos/ das estudantes, tendo em vista que, com idades aproximadas, têm-se como referência suas potencialidades e as características que apresentam nas diferentes fases da vida. E, sendo assim, a proposta curricular deveria considerar que o desenvolvimento humano decorre "das mediações provocadas pelo meio sociocultural (...) em relação dialética com o desenvolvimento biológico" (FETZNER, 2009, p. $55)$.

${ }^{6}$ Atendendo ao disposto na lei 11.738/2008, a Rede Municipal de Ensino do Rio de Janeiro regulamentou, a partir do ano de 2012, a obrigatoriedade de destinação de $1 / 3$ da carga horária semanal do professor para planejamento. Foi sugerido que este tempo fosse organizado em um dia com quatro horas e meia, mais um dia com 1 hora semanal e mais
} 


\section{Per a}

engendrou um movimento por reestruturação do documento por parte dos sujeitos envolvidos na pesquisa. Trata-se de uma escola localizada em uma área de ocupação não planejada, na Zona Oeste do município do Rio de Janeiro, que atendia a estudantes do $1^{\circ}$ ao $5^{\circ}$ anos do Ensino Fundamental em dois turnos e que contava com doze turmas do ciclo de alfabetização no ano de realização da pesquisa. A comunidade apresentava uma grande demanda por serviços de saúde, educação, lazer, limpeza urbana, entre outros.

A análise dos documentos que registravam o planejamento dos professores, assim como a fala das professoras, permitiu verificar que elas conseguiam perceber necessidades no trabalho cotidiano. Conseguiam incluir conteúdos não previstos no documento curricular prescrito em âmbito governamental, mas que estavam em consonância com o Projeto Político Pedagógico (PPP) ou o projeto de trabalho anual da escola - ou, ainda, que eram percebidos por elas como necessários à formação do/da estudante:

Eu tenho uma visão muito globalizada do que eu tenho que aplicar. Então, isso aqui [apontando para as Orientações Curriculares] eu dou uma olhada. Realmente... eu tenho que estudar isto aqui, porque isto aqui é a bíblia atual, né? É. Isso aqui é a bíblia atual da educação. Eu dou uma olhada. Eu tenho. Mas (...) Cadê a comunidade escolar inserida aqui? Cadê a nossa realidade? (...) Isso aqui não está dentro da nossa realidade! (Professora A)

Ao mesmo tempo, por conta das avaliações externas que chegavam à escola ao longo do ano, percebeu-se, por parte de muitas delas, a preocupação em desenvolver as "habilidades" que seriam verificadas nessas avaliações, em um visível movimento de indução curricular, tal como sinalizado por Freitas (2012) e que parece ir ao encontro da fala de outra docente quando esta afirma: "As provas, elas são baseadas na apostila. Então

trinta minutos 4 vezes na semana, perfazendo um total de sete horas e meia de planejamento semanal para uma carga horária de trabalho de vinte e duas horas e meia semanais. A condução das atividades nesse espaço de planejamento nas escolas ficou a cargo dos coordenadores pedagógicos. 


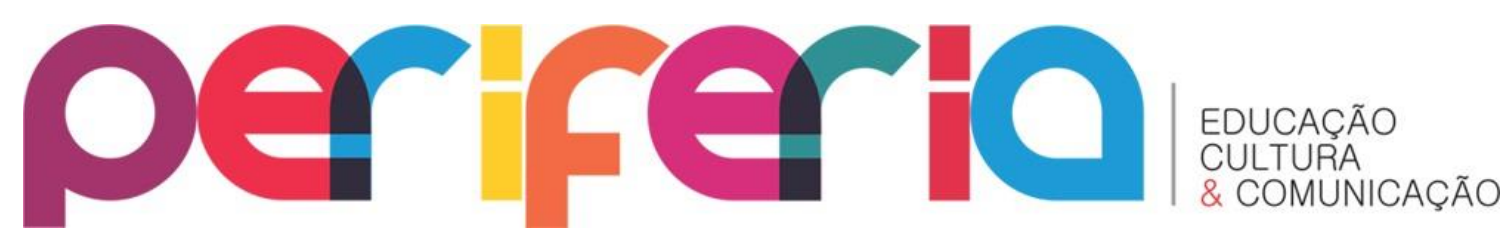

isso acaba fazendo com que a gente, entre aspas, assim, domestique o aluno pra atingir aquilo dali". (Professora B)

Tal movimento por elas realizado revelou diferentes relações com o que era prescrito em nível governamental: profissionais que realizavam uma leitura crítica e conseguiam estabelecer um distanciamento em relação ao que era prescrito quando percebiam que não atendia às necessidades identificadas; outras que - apesar de realizar uma leitura crítica - não conseguiam distanciar-se dela quando em desacordo com o que acreditavam e/ou percebiam como necessidade. Assim, perceberam-se diferentes relações com o documento curricular que chegou à escola pesquisada. A análise e observação permitiu constatar que este posicionamento revelou-se em íntima relação com a formação que têm os profissionais e/ ou os anos de experiência no magistério. Assim, a investigação permitiu constatar que o currículo elaborado nas instâncias governamentais, ao chegar ao ambiente escolar passou por um processo de hibridismo tal como o termo foi concebido por Bhabha (1998) e está sendo aqui apropriado para pensar o ambiente escolar:

Um discurso crítico não produz um novo objeto, uma nova meta ou saber político que seja um simples reflexo mimético de um princípio político ou comprometimento teórico a priori. (...) A linguagem da crítica é eficiente não porque mantém eternamente separados os termos do senhor e do escravo, do mercantilista e do marxista, mas na medida em que ultrapassa as bases de oposição dadas e abre um espaço de tradução: um lugar de hibridismo, para se falar de forma figurada, onde a construção de um objeto político que é novo, nem um e nem outro, aliena de modo adequado nossas expectativas políticas, necessariamente mudando as próprias formas de nosso reconhecimento do momento da política. (BHABHA, 1998, p. 51)

Nesse trabalho de investigação, as percepções docentes acerca da proposta para a Casa de Alfabetização puderam ser captadas por meio de algumas categorias: o movimento de indução curricular, a relação com as Orientações Curriculares, a relação com os Cadernos de Apoio Pedagógico e a concepção de ciclo que orientava o trabalho das professoras. No que tange ao 


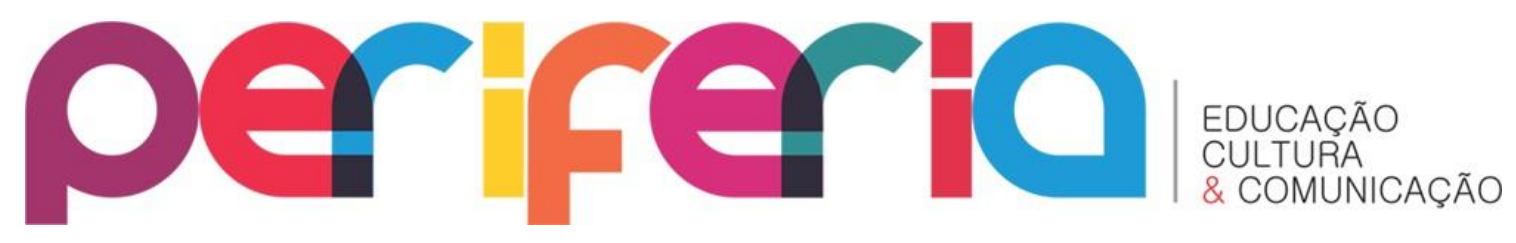

primeiro item, conforme já exposto, ficou visível para elas que os materiais encaminhados à escola estavam estruturados para valorizar determinados aspectos do currículo proposto. Em relação à leitura que fizeram das Orientações Curriculares, essa variou conforme a combinação de formação e tempo de exercício do magistério. Assim, algumas conseguiram estabelecer uma crítica e empreender o trabalho que julgavam necessário para a realidade que tinham; outras, ao contrário, ainda não conseguiam perceber a concepção de educação que ali era preconizada. Quanto à relação com os Cadernos de Apoio Pedagógico - espécie de "apostila com atividades pedagógicas" para os/as estudantes - houve unanimidade em afirmar que utilizavam-na na medida em que poderiam contribuir com o trabalho, embora algumas se sentissem condicionadas a realizar as atividades propostas, por conta das avaliações externas a que os/as estudantes seriam submetidos/as.

Em função do trabalho realizado nos momentos dedicados aos Centros de Estudos (estudos e planejamentos coletivos), foi-se afinando no grupo uma concepção de ciclo que preconizava a progressão continuada. Assim, emergiram críticas à forma como o ciclo está estruturado na rede municipal, especialmente no que tange à questão da avaliação nesse agrupamento e à pouca clareza acerca dos termos alfabetização e letramento no documento curricular, conforme evidenciado na fala de uma das professoras.

\section{CONSIDERAÇÕES FINAIS}

A investigação permitiu identificar diferentes posicionamentos dos professores e professoras da escola em relação às propostas oriundas das instâncias governamentais e que tais posicionamentos estão intimamente relacionados à combinação de formação acadêmica e experiência no exercício do magistério. A imersão deles/ delas no cotidiano da escola faz com que percebam necessidades/ conteúdos que, muitas vezes, não estão previstos no currículo proposto em nível governamental e que estão relacionados às suas 


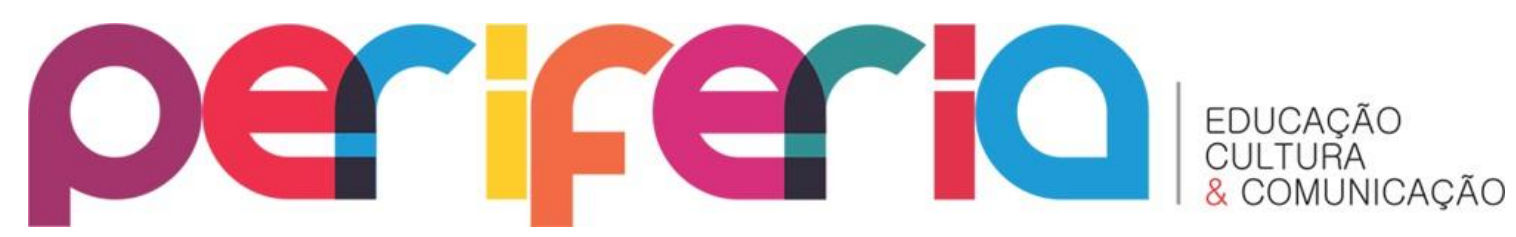

vivências pessoal e profissional, à sua formação e ao diálogo com os/ as estudantes.

A investigação mostrou que os professores e professoras são subalternizados no processo de estruturação curricular e que, estando em contato direto com a comunidade escolar - percebendo suas reais necessidades - podem contribuir sobremaneira para aquele processo. É preciso existir espaços para que o diálogo entre as instâncias governamentais e as escolas se efetive e resulte na elaboração de diretrizes que realmente tenham significado para a escola, seus professores e estudantes. O que observei na implantação da Casa de Alfabetização - e ela como parte de uma proposta curricular maior, implementada a partir de 2009 - foi que, não havendo diálogo com os profissionais por ocasião da estruturação da proposta, estas foram "lidas" por eles, emergindo destas "leituras" significações diversas e que estavam em relação estreita com o nível de qualificação dos professores e com fatores relacionados ao contexto próprio aonde chegou.

Com o novo ordenamento que as políticas neoliberais estabeleceram para o campo da educação, diversos governos municipais se alinharam com propostas centralizadoras. No município do Rio de Janeiro, com a ascensão de uma nova administração a partir de 2009, configurou-se uma política que focou nas avaliações externas, que foi se intensificando desde então e acabou promovendo um movimento de indução curricular. A análise das falas docentes e dos materiais produzidos (Orientações Curriculares, Cadernos de Apoio Pedagógico para estudantes, planejamento docente) permitiu verificar que professores e professoras têm posicionamento crítico em relação à nova política. Sua formação, convicções pessoais e experiência, além de fatores próprios do contexto é o que thes permite distanciar-se, em maior ou menor grau, da orientação da política governamental, conforme dito anteriormente. Assim, os significados que emergem da relação entre o documento curricular oriundo da política governamental e as concepções e práticas dos professores e professoras nas escolas, são aqueles relacionados à história profissional e de vida de cada um/ uma. 


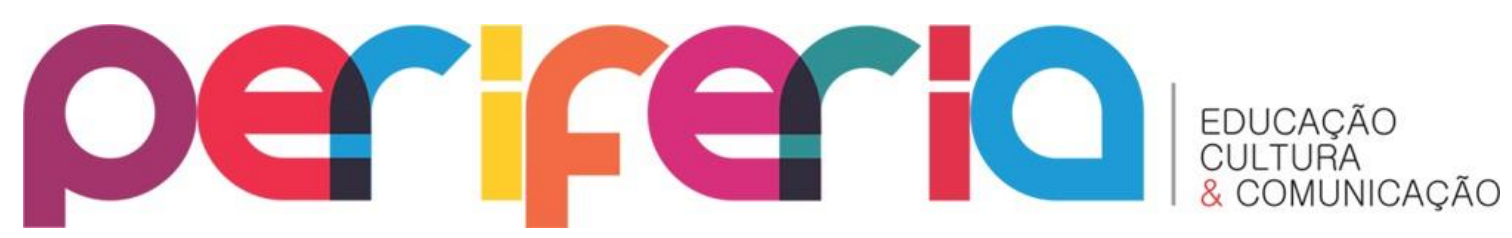

\section{REFERÊNCIAS}

BALL, S. J. Performatividade, privatização e o pós-Estado do bem estar. Educação e sociedade, Campinas, v.25, n.89, p. 1105-1126, set/ dez 2004.

BHABHA, H. K. O local da cultura. Belo Horizonte: Editora UFMG, 1998.

CHIZZOTTI, A. Pesquisa qualitativa em ciências humanas e sociais. Petrópolis: Vozes, 2006.

FETZNER, A. R. A implementação dos ciclos de formação em Porto Alegre: para além de uma discussão do espaço-tempo escolar. Revista Brasileira de Educação, Rio de Janeiro, v. 14. n. 40, jan./abr. 2009.

FREITAS, L. C. de. Os reformadores empresariais da educação: da desmoralização do magistério à destruição do sistema público de educação. Educação e Sociedade, Campinas, v. 33, n. 119, p. 379-404, abr. jun. 2012.

GARCIA, M. M. A. Políticas educacionais contemporâneas: tecnologias, imaginários e regimes éticos. Revista Brasileira de Educação, Rio de Janeiro, v15. n.45, set./dez. 2010.

PARO, V. H. O currículo do Ensino Fundamental como tema de política pública: a cultura como conteúdo central. Ensaio: aval. pol. públ. Educ., Rio de Janeiro, v. 19, n. 72, p. 485-508, jul./set. 2011.

BRASIL. Lei 11.738 de 16/07/2008. Disponível em: $<$ http://www.planalto.gov.br/ccivil_03/_Ato20072010/2008/Lei/L11738.htm>. Acesso em 15 jan. 2014.

PORTAL TODOS PELA EDUCAÇÃO. Disponível em: $<$ www.todospelaeducacao.org.br>. Acesso em 05 mar. 2015 